\title{
Castilla y León, un territorio cuestionado: Retóricas del espacio y del tiempo en la construcción de identidades
}

\author{
Castile-Leon, A Mooted Territory: \\ Rhetoric of Space and Time in the Construction \\ of Identities
}

\author{
Luis Díaz Viana \\ Grupo de Investigación "Antropología Comparada \\ de España y América" (ACEA) \\ Centro de Ciencias Humanas y Sociales. CSIC. Madrid
}

\section{RESUMEN}

En la construcción de identidades en el presente se suele traer a colación el tiempo - lo que se fue en el pasado- a la vez que se reclama un espacio - lo que se debería ser hoy en términos de territorialidad-. Sin ser ésta una característica exclusiva de las identidades que se reivindican dentro de España, parece claro que sí se trata de una estrategia empleada con particular intensidad aquí, una vez se produjo la transición política tras el franquismo. Pero, dentro de este panorama, se esgrimirían dos retóricas distintas y hasta opuestas de reconquista del ayer: una histórica y otra mítica. Según la primera, habría que volver a ser y tener lo que se fue y tuvo en algún momento del pasado. Según la segunda, se reivindicaría volver a ser lo que - supuestamente- siempre se fue como pueblo, aunque nunca esa aspiración de identidad hubiera llegado a tener traducción territorial clara ni comprobación documental. ¿Cuál es el caso en la Comunidad Autónoma de Castilla y León? Los estereotipos que a menudo ofrecen de Castilla (el componente clave en la Comunidad) políticos, analistas y escritores hablan de un territorio cuestionado y de un pueblo que parece desentendido o ignorante de sí mismo. El autor aborda y, en cierto modo, deconstruye estos estereotipos (mitad cultos y mitad populares), intentando desentrañar — además— otras claves para mejor comprender esa aparente "falta de identidad" o "de consciencia regional" que se achaca a lo castellano y los castellanos.

Palabras clave: Retórica de la identidad, Espacio, Tiempo, Historia, Mito, Comunidad Autónoma de Castilla y León, Castilla, Consciencia regional. 


\section{SUMMARY}

In constructing identities of the present, time (the past that was) as well as space (the territory that should be) is conjured up. Although this manner of operation is not a distinctive feature of identity construction in Spain, it is clearly a strategy employed here in earnest once the political transition to democracy was over. This strategy comprehends two different, opposite rhetoric modes regarding claims of the past: one historical, the other mythical. The first prompts the audience to become again what it once was and to recover what it at the time held. The second calls for a reencounter with that which, supposedly, always defined it as a people, even though this people never fully realized its territorial aspirations in the past or no written evidence exists that it ever held the territory that it now claims as its own. Which is the case in the "Autonomous Community of Castile-Leon"? Stereotypes about Castile (the key component in this Autonomous Community of contemporary Spain) uttered by politicians, analysts and writers make reference to a mooted territory and to a people apparently heedless and ignorant of itself. The author approaches and, in a way, deconstructs these stereotypes, half of them learned, the other half popular. In addition, he attempts to expose other reasons that lie behind such seeming "lack of identity" or "of regional consciousness" that presumably plague Castilians and everything Castilian.

Key Words: Rhetoric of Identity, Space, Time, History, Myth, Autonomous Community of Castile-Leon, Castile, Regional Consciousness.

En muchas de las historias que escuché de niña las protagonistas eran mujeres que bajaban, al cobijo del amanecer o al atardecer, a las lindes de los huertos donde otras mujeres trabajaban con sus bebés durmiendo en los linderos. Bajaban descalzas, sigilosas entre la maleza, y dejaban a sus hijos en el lugar de los de las campesinas, llevándose a éstos como pequeños rehenes. Las más de las veces sólo querían que les bautizaran a los niños.

- Acachenta, acachenta, que el tuyo acachentado está.

Sólo buscaban darles un porvenir a sus hijos en un mundo que ya no iba a ser nunca más el suyo. La vida de estos moros (y digo moros como siempre lo oí) quedó dibujada en nuestro paisaje con la marca de su condición de proscritos. Pastoreando el ganado, mi madre me mostró muchas veces sus cuevas, siempre elevadas, con buena perspectiva, en posición de perpetuo acecho. Debo decir que nunca percibí rencor contra los moros de estas historias. Cuando un bebé se dejaba en un ribazo era invariablemente bautizado y devuelto con los suyos a cambio del propio, que siempre se devolvía sano y salvo. A veces, las madrinas improvisadas acababan acogiendo a los niños si sus madres enfermaban o morían y educándolos como a sus propios hijos.

(Testimonio escrito de $\mathrm{M}^{\mathrm{a}}$ Carmen Álvarez, Salientes, Alto Bierzo, 2005) 
I. RETÓRICAS DEL ESPACIO Y DEL TIEMPO: EL MITO Y LA HISTORIA COMO ARGUMENTOS DE REIVINDICACIÓN TERRITORIAL

Lo primero que cabe señalar respecto a la construcción de identidades en el presente es la retórica dual que suele utilizarse para sus argumentos y reivindicaciones. Generalmente, se trae a colación el tiempo - lo que se fue en el pasado- para reclamar un espacio - lo que se debería ser hoy en términos de territorialidad-. Sin ser ésta una característica exclusiva de las identidades que se reivindican dentro de España, parece claro que sí se trata de una estrategia empleada con particular intensidad aquí, una vez se produjo la transición política tras el franquismo. No era, desde luego, nada original. Ya en la Europa revuelta y descolocada —en lo territorial, en lo social y en lo político- que dejó la tormenta napoleónica, surgirían a lo largo de todo el siglo XIX nuevas identidades que, sin embargo, se reclamaban viejas para justificar sus reivindicaciones territoriales.

Entonces, como ahora en el caso español, se esgrimían dos retóricas distintas y hasta opuestas de reconquista del pasado: una histórica y otra mítica. O, si se prefiere, una que aludiría a antiguas realidades político-administrativas y otra que apelaría a una metafísica que podríamos llamar étnico-legendaria. Según la primera de estas estrategias habría que volver a ser y tener lo que se fue y tuvo en algún momento del ayer: por ejemplo, derechos, competencias y privilegios como reino, región o nación. Según la segunda, se reivindicaría volver a ser lo que — supuestamente- siempre se fue como pueblo, aunque nunca esa aspiración de identidad hubiera llegado a tener traducción territorial clara ni comprobación documental.

Para la primera clase de reivindicación se acostumbra a recurrir a la historia; para la segunda, al mito. Y, en ambas retóricas, se apela como elemento distintivo — que demostraría la diferencia mantenida respecto a otrosa la lengua. El caso del nacionalismo catalán, que reivindica — sobre todouna nacionalidad y un país o países perdidos parece ajustarse al primer tipo de identidad y de retórica. El caso vasco, que reclama la libertad e independencia de un pueblo ancestral, encajaría mucho mejor en el segundo.

Pero ¿qué pasa con Castilla? Castilla, en la primera década del siglo XXI se nos presenta como un territorio cuestionado y un pueblo que parece desentendido o ignorante de sí mismo. Hemos oído decir — hace ya un tiempo- a algún sociólogo ocurrente (Amando de Miguel) que los castellanos, al igual que los judíos, eran un "pueblo-linaje". Quizá la comparación se debiera a que unos y otros han tenido en común la "diáspora": "La población de los castellanos está constituida por el pueblo de Castilla y León y por los castellanos que residen fuera" (De Miguel y Moral 1984: 37). Pero, si eso fuera así, los castellanos serían castellanos en todas partes y no da la 
impresión de que lo castellano sea una religión o una raza distintiva entre las demás, sino un referente cultural ligado a una lengua y —más que un territorio- a unas tierras o a un paisaje (que son también muchos paisajes). O, mejor, una manera de entenderlos y expresarlos: una forma más o menos específica de entender el mundo y estar en él. Un castellano fuera o lejos de Castilla es, probablemente, un castellano a medias, mientras que un judío lo es en cualquier lugar y hasta puede reinventarse un país en una tierra donde él nunca había estado antes (aunque sus antepasados sí). ¿Castilla es entonces, y sobre todo, la "tradición y el idioma"? Eso sostendría —cuando soplaban vientos imperiales- Menéndez Pidal (1945). Pero no consiste en eso sólo. Ni en el estereotipo noventayochista de un paisaje tampoco, pues hay muchos paisajes y muchas Castillas dentro de lo castellano.

Castilla, ahora, no es únicamente un territorio cuestionado, sino una Comunidad Autónoma — “Castilla y León”—con una noción más bien vaga de territorialidad. Los leonesistas, dentro de ella, reivindican una identidad que podría entenderse "a la catalana", es decir, como una reclamación de derechos históricos más o menos manipulados con el retoque de lo identitario. León fue un reino independiente una vez, sí, pero antes y después de eso también fue muchas cosas. Castilla ¿qué territorio reivindica si es que algo puede reivindicar? Quedó, algo azarosamente y no sin apresuramientos, ligada a León en los repartos autonómicos pactados casi en secreto. Pero, si se mira hacia el pasado, también fueron Castilla la actual Rioja, Cantabria, Castilla la Nueva (hoy Castilla-La Mancha) y, en definitiva, gran parte de España. Esa mirada territorialista hacia atrás produciría, pues, casi vértigo.

El repaso de los estereotipos sobre los supuestos caracteres de los habitantes de los distintos territorios de la nación tampoco pasaría de entretenimiento curioso. Baste al respecto con hojear alguno de los pliegos de Literatura de Cordel que contienen prolijas relaciones acerca del "carácter, genio y condiciones que tienen los habitantes de las provincias de España"; como el que mostramos en el apéndice a este ensayo, tomado del Catálogo de pliegos de la viuda de Hernando conservado en la Real Academia Española.

\section{De la Supuesta falta DE identidad De los Castellanos y OtROS CuRiosos ESTEREOTIPOS}

De otro lado, ¿cómo se identifican Castilla, los castellanos y lo castellano en cuanto a pueblo? Curiosamente, no se duda de que exista lo castellano, pero sí de que los castellanos tengan identidad o, al menos, consciencia de ella. Es ya un tópico pensar que hay un comportamiento castellano que depende de un carácter, el del campesino, y que éste —ignorante del 
valor de sus propios saberes y, con ello, de su identidad- actúa de forma retrógrada, contraproducente para su futuro y el de sus descendientes. Se ha aducido a menudo que, al diluirse - económica y políticamente- en la empresa de lo español, Castilla, además de pobre, quedó despersonalizada, perdió consciencia y carácter. Pero itienen los pueblos, las naciones o los pueblos-nación carácter como las personas? Caro Baroja lo dudaba e ironizó sarcásticamente y "a contrapelo" contra los defensores de los caracteres nacionales (Caro Baroja 1970).

En Castilla, más que en ninguna parte e incluso de una forma que no sucede casi en ningún otro lugar, son los propios políticos los que se lamentan de una carencia de consciencia o sentimiento identitario por parte de sus conciudadanos. No habría aquí consciencia de región - aseguran-. Y en ello siguen a los escritores, que han pasado a convertirse en "autoridad científica", citada hasta por ciertos sociólogos que se ocuparon y ocupan de la identidad castellana. No voy a reproducir, por conocidas, las muchas elucubraciones que literatos de postín han tejido sobre Castilla y lo castellano, desde la "Generación del 98" hasta Miguel Delibes. La mayoría de sus visiones al respecto están centradas en un supuesto carácter castellano al que se relaciona con un estereotipado paisaje de pelados páramos; y no pocas también son visiones del campesino que los habita, lo que no deja de tener un regusto muy romántico. El paisaje habría hecho el carácter y ambos se condensarían perfectamente en el fenotipo de un campesino eterno, que apenas habría cambiado a pesar del paso del tiempo. Ha escrito, así, Delibes (1979: 225) que el castellano es "juicioso, sumiso, lacónico, seco, austero, fatalista"; y el campesino de estas tierras un ser "casi paleolítico en la segunda mitad del siglo Xx".

Ya los folkloristas románticos de toda Europa habían mirado hacia atrás encontrándose con unos campesinos que - para ellos- encarnarían las esencias de un pueblo inalterable e inalterado. Pero la visión de los escritores sobre este campesinado castellano, lejos de ser idealizadora resulta, como dirían Passeron y Grignon (1992), "miserabilista". Es decir, nada halagüeña. Una visión que liga —a menudo- la pobreza material con una más que probable miseria espiritual o moral. De "los palurdos sin danzas ni canciones" que pintara Machado, pensando en los campesinos de Soria, a los "seres neolíticos" inadaptados al mundo actual que describe Delibes — con sus correrías cinegéticas por Valladolid y Burgos en la retina-, poco bueno parecen haber encontrado uno y otro en los campesinos que se topaban.

La aseveración de Antonio Machado resulta especialmente inexacta e injusta para venir de la pluma del hijo de un folklorista. Lo que decía Delibes ha sido matizado después por el propio escritor, quien en alguna obra tardía pasaría de la visión "miserabilista" de lo popular a la "idealizadora" o 
mitificadora, trazando una imagen idílica del buen campesino, el señor Cayo, que tanto tendría que enseñar a los jóvenes que van de progresistas. Machado negaba los saberes de sus palurdos y Delibes acaba redescubriéndolos y ensalzándolos como modelo opuesto a la postmodernidad.

La afirmación de Machado era — a todas luces - inmerecida: las recopilaciones llevadas a cabo por folkloristas venidos de fuera como Schindler (1941) o Espinosa (2009 [1946-47]) demostrarían sobradamente que aquellos palurdos no sólo conservaban sus danzas y canciones, sino que fue - precisamente- en tierras castellanas donde uno y otro pudieron recoger más cantos y cuentos que en ningún otro lugar de España. Ambos, además, reconocerían su asombro y casi su deslumbramiento ante el caudal de esa riqueza atesorada por generaciones.

Respecto a la idea, compartida por Delibes y otros autores no sólo literarios, sino también de diversos campos de las ciencias sociales, de que el campesino castellano es arcaico y conservador a ultranza - hasta la autodestrucción- cabe decir que queda, al menos en parte, desmentida por recientes estudios antropológicos. María Àngels Roque ha puesto de manifiesto - por ejemplo- cómo los habitantes del valle por ella estudiado en la Sierra de la Demanda burgalesa, lejos de desaparecer como pueblo - que tal era el fin inminente que les habían pronosticado análisis anteriores - se han adaptado como han podido a las nuevas circunstancias. E incluso han incorporado el tradicional sistema de "turnos" a nuevos proyectos comunes de resurgimiento, para poder reconstruir - así - solidariamente antiguos edificios que amenazaban ruina (Roque 2008). En ése como en otros pueblos que sí parecen sufrir un despoblamiento irreversible, se aprecia el afán —consignado por Stanley Brandes- de mantener, además, no sólo viva la comunidad sino también la relación con ella. Cosa que se consigue, siquiera virtualmente, por parte de quienes, estando fuera, establecen sociedades en red para - desde webs que historian y promocionan el lugar natal- contribuir a su vigencia. Así, en el caso de la abulense localidad de Becedas a la que Brandes se refiere (Brandes 2007).

La interpretación que, en clave político-social, a menudo se ha hecho del sentido del voto en Castilla como muestra del conservadurismo reaccionario de su campesinado, dice — probablemente- más de quienes lo juzgan que de quienes votan. Pues la izquierda clásica, proclive por su herencia marxista a entender la economía desde la perspectiva de la producción industrial, no ha sabido — ni ha querido, quizá- entender los problemas de los campesinos castellanos. Asumiendo que, tradicionalmente en las elecciones españolas, las grandes ciudades industrializadas suelen votar a la izquierda y el campesinado o los pequeños pueblos a la derecha, aquélla no ha hecho casi nada por cambiar esa tendencia, como si aceptara de ante- 
mano que en el proletariado explotado sí puede prender la llama revolucionaria o - al menos, de un cierto progresismo-, pero en el campesino - muchas veces igual o más esquilmado por los poderosos-, no. Ahí sí que acierta plenamente Delibes cuando denuncia y critica, en El disputado voto del señor Cayo (1990), el — generalmente- ciego y sordo progresismo de la ciudad frente al campo. Pero es que la izquierda política actual en la Comunidad Autónoma de Castilla y León ha preferido - a lo que se vedar por perdido de antemano un predio considerado - por campesinocomo conservador y reaccionario, a tomarse el trabajo de conocer cómo esos campesinos son y piensan o — sobre todo- qué es lo que necesitan. Y resulta trabajoso, sí, recorrer tanto pequeño pueblo del que (tras mucho discutir) sólo se puede arrancar un exiguo puñado de votos. Sin embargo, el PSOE ganó en las primeras elecciones para el gobierno de la Comunidad —en 1983 - y ningún analista ha sabido explicar exactamente por qué si los campesinos son tradicionalmente tan conservadores. Por qué el PSOE perdió todas las elecciones posteriores podría explicarse — sencillamentepor los propios errores políticos de la izquierda: entre ellos, el de la miopía ante una región en que una población campesina de pequeños propietarios — no de jornaleros — sigue pesando de forma muy importante.

Otro aspecto que si no desmiente sí permite matizar el cacareado conservadurismo campesino es el señalado por Brandes (2007) y otros autores que nos hemos ocupado del tema (Díaz Viana 1988: 24), de que los campesinos han apostado - frecuentemente- en Castilla y León por un tipo de vida y trabajo radicalmente distinto al que ellos habían tenido como mejor futuro para sus hijos: darles una carrera, unos estudios, una educación. ¿Por qué interpretar que lo progresista en un campo depauperado por los sucesivos fracasos de reforma agraria hubiera sido que los padres pusieran un negocio rentable a sus vástagos? ¿No es más progresista el preocuparse por dotarles de una educación? Y no sólo a los varones, de manera especial en algunas zonas, también a las mujeres que llevarían así las cuentas y escribirían cartas mucho mejor que los hombres. El resultado de pensamientos tan conservadores ha sido que Castilla y León constituyera, ya desde hace tiempo, una de las zonas de España que presentaba un índice menor de analfabetismo. Una Comunidad que exportaba maestros/as y funcionarios/as en una gran proporción a otras. Y lo sigue siendo.

III. LAS CRONOTOPÍAS DE LA IDENTIDAD: ENTRE LA HISTORIA, EL MITO Y EL LENGUAJE

Pero volvamos a las cronotopías del discurso identitario. Es decir, al funcionamiento del modelo que algunos autores han definido como "cro- 
notópico" (Cruces 1997: 54) en el caso castellano. ¿Qué falla o qué no se entiende de una identidad castellana que — a pesar de lo que puedan pensar escritores y políticos- existe? Porque, además, antropológicamente no puede dejar de existir. El sociólogo Alfredo Hernández ha desmentido esa idea de que "como la historia de Castilla ha consistido en haber hecho a España, el sentimiento castellano se ha diluido en el sentimiento españolista y, por esta razón, no existe consciencia regional” (Hernández 2004: 97). Como acertadamente señala este autor, "una cosa es Castilla como metarrelato, como constructo político-ideológico, construido por las élites del Estado español, y otra cosa muy diferente la historia social, demográfica, económica y política de esta comunidad" (ibid: 97). No obstante, tal aseveración debe ser matizada.

La retórica de las identidades no sólo se construye sobre fragmentos de historia, sino también sobre la memoria etnográfica, sobre un tiempo mítico. Y generalmente resulta de una combinación de lo que cuentan e intentan imponer las elites y de lo que es interiorizado y repetido por quienes no lo son, llamémosles —si se quiere-clases populares. Aunque algunos siempre preferiremos hablar de cultura popular - en la cual las elites también serían partícipes - que de clases. Y ese metarrelato del que habla Hernández es una mezcla o resultante de lo histórico y de lo mítico. De hecho, el imaginario español manejado por las elites estatales se basa en buena medida en narraciones míticas de origen castellano, empezando por las leyendas y romances de Bernardo del Carpio, Fernán González o el propio El Cid. En los mitos de lo castellano se enraíza el concepto de lo español, la identidad española, que los toma prestados y en ellos se confunde. Pero ¿recuerda Castilla sus mitos? Las leyendas y romances que se han seguido cantando y contando sobre determinados personajes y lugares apuntan a que sí (Díaz Viana 1997: 46-47).

Ya quedó dicho anteriormente que la cronotopía identitaria aduce argumentos históricos o míticos para justificar reclamaciones de un territorio, tan ideal — por lo demás - como el pasado reconstruido en esa retórica. Ya se trate de los paísos catalans o de una Euskalerria que incluiría Navarra y determinadas áreas españolas o francesas. No sabemos si también con el tiempo se podría reclamar, por ejemplo, el Estado norteamericano de $\mathrm{Ne}$ vada por la gran presencia de pastores y ganaderos vascos allí. Pues la estratagema mítica de reclamar gentes y territorios no tiene límite, como bien señalaba Finkielkraut al referirse a la reincorporación a Alemania — tras la guerra de 1870 - de las provincias francesas de Alsacia y Lorena, contra la opinión de los habitantes de éstas (Finkielkraut 1987: 31-37). El espíritu mítico reconoce a los suyos incluso si los suyos no se reconocen: habláis o habéis hablado nuestra lengua, sabéis nuestras canciones, tenéis nuestra cultura, sois 
por lo tanto nuestros sin saberlo o quererlo. Así actúa la voracidad reivindicadora del genio mítico.

¿Pero qué territorialidad aspiraría a recuperar el genio castellano? Castilla es — si no resulta demasiado redundante o políticamente incorrecto- el mito originario, por excelencia, de lo español. Rodrigo "perdió España" cuando todavía España no podía existir (gracias a la reconstrucción mítica del pasado que surge de Castilla) y con Fernán González — mucho más que con Don Pelayo- empieza también míticamente a recobrarse. Por lo tanto, territorialmente, Castilla podría reclamar todo el espacio en que ese mito llegó a alcanzar proyección. Pero, políticamente, esta reivindicación hoy es inimaginable que pudiera prosperar. Y es esto mismo lo que lastra y entorpece la gestión del mito de lo castellano. Pues ¿qué territorios reivindicar? ¿Por dónde empezar a anexionarse las proyecciones míticas de Castilla?

Recurrir al mito o la historia para justificar cronotopías reivindicativas es, en el caso de la retórica castellanista, casi igual de complicado. De la nada al todo y del todo a la nada cualquier opción puede ser teóricamente justificable. Sin embargo, y en esto Hernández tiene también razón, las reivindicaciones formuladas políticamente desde Castilla se basan casi exclusivamente en motivos históricos: en lo que se fue. Se echa demasiada historia en el discurso reivindicativo castellano y esa historia repleta de viejas glorias puede llegar a pesar mucho, e incluso "políticamente hablando" demasiado (Hernández 2004: 97). Y, sobre todo, resultar demasiado lejana. Una campaña reciente de la Junta de Castilla y León seguía incidiendo en lo mismo, aunque fuera con el lenguaje de la publicidad actual: consistía en imágenes de personajes históricos del pasado castellano que decían: "Castilla y León tiene gracia". Y el personaje nos respondía: "Sí, la tiene”. Quien lo viera probablemente no encontraba la gracia por ningún lado, pero el mensaje de que la "gracia" de Castilla y León está ligada a la historia — y a un pasado ya desaparecido- quedaba bastante claro.

Los políticos que gobiernan Castilla y León no van más allá. O sea, que en identidad avanzan muy poco y se podría decir que - manifiestamentesuspenden la asignatura. No se recurre a las fuentes míticas —quizá porque los gobernantes castellanos y leoneses estén convencidos de que la historia es verdad y el mito mentira- y se desaprovecha una veta culturalmente muy importante que, además, es —quizá- la que tiene prestigio en el mundo: la épica, los romances, el teatro barroco (más legendariamente castellano que nacional), los lugares con leyenda...

De otra parte, el resorte de acudir a un pueblo mítico y eterno (como de hecho se practica, abusándose de él, en el nacionalismo vasco) no tendría mucho sentido. Ningún castellano en sus cabales se tendría por étnicamente puro. Se asume comúnmente —y de manera más bien vaga— 
en Castilla que los castellanos son una mezcla de celtíberos, romanos, visigodos, árabes y lo que viniera después. Se trata de una homogeneidad aparente o variada, además de variable, puesto que las dosis de lo uno y lo otro se encuentran desigualmente distribuidas según las zonas. En esto las creencias populares coinciden bastante con la historia. Lo de que los castellanos se identificaran como cristianos viejos es una invención más bien tardía que no se produce hasta finales de la Edad Media, cuando la combinación de todos estos elementos étnicos ya había tenido lugar profusamente durante los siglos anteriores. La distinción parece producirse, de otra parte, más por motivos religiosos y hasta económicos que por los propiamente raciales. Pero a ello convendrá volver luego.

¿Cómo identificar lo castellano, pues? Sólo queda la cultura, sólo la lengua. El mismo Delibes, sin embargo, apunta en el tono pesimista que caracteriza a sus visiones sobre el tema que en Castilla "no existe una consciencia histórica y cultural profunda" (1979: 16-18); y es de suponer que ello sucede -como el propio autor también ha comentado en muchas ocasiones- porque la lengua castellana, por extensa y difundida a través del mundo, no sirve como seña de identidad. Tampoco es del todo cierto. Dos cosas definen —en nuestra opinión - a lo castellano, o si se prefiere a la identidad castellana. El sentimiento de pertenencia a un lugar y el uso correcto (según los parámetros castellanos) de un lenguaje. Es —como ha señalado Velasco - el sentido de pertenecer a un lugar, el pueblo (en el caso del medio rural) lo que destaca con más fuerza entre los niveles de identidad a los cuales los castellanos pueden adscribirse: "Cuando un castellano habla de su pueblo está hablando de su 'naturaleza', una 'naturaleza' que es a la vez su lugar de origen y su grupo humano de origen" (Velasco 1998: 28-46). Luego está el horizonte de la comarca y, más allá, poco más, una vaga idea de región y - en contra de lo que muchas veces se piensa - una vaga idea de país nación, que sólo cobra sentido en la medida que se identifica con la Castilla local de cada uno. La idea de que los castellanos se identifican con la invención bastante reciente de las provincias es algo — precisamente- que sólo en las ciudades puede aceptarse como plausible. Hay muchos casos, además señalados por antropólogos como Kavanagh (1994), que apuntan a que los castellanos de determinadas sierras consideran más su capital a la ciudad de cierta importancia que hay al otro de la montaña —y que pertenece ya a otra demarcación provincialque a la de su propia provincia. Tal sucede con los trashumantes de la sierra de Gredos en sus sentimientos tradicionalmente positivos hacia Plasencia y no tanto hacia Ávila capital (Kavanagh 2007). Pero a los políticos que han gobernado Castilla y León no les ha interesado remover la - para ellosjugosa separación en Diputaciones provinciales que tanto poder y recursos 
les proporcionaba. De ahí que la comarcalización —etnográfica, geográfica y administrativamente recomendable- de Castilla y León haya sido siempre sistemáticamente aplazada (Díaz Viana 1995: 179).

Regresemos al problema del lenguaje como seña identitaria. El lingüista Santiago de los Mozos escribió atinadamente a este respecto que "la peculiaridad de una región puede consistir más que en la defensa de esa peculiaridad (lingüística) en el reducto de los confines originarios, en la expansión de la misma” (De los Mozos 1984: 99). ¿Cuándo y cómo sabe un castellano que se aleja de su tierra o, mejor, de esa pequeña patria que es su ciudad o su pueblo? Porque en su Comunidad también se habla el astur-leonés. Cuando le empiezan a hablar con otro acento o a utilizar un vocabulario que no controla del todo. Entonces, rápidamente tiende a interpretar que los que hablan lo hacen en castellano, pero que lo hablan "mal". Todavía en algunos lugares de América se llama a hablar en castellano - por parte generalmente de las poblaciones indígenas- "hablar la Castilla". Los castellanos son ese tipo de personas, que como algunos ingleses o franceses creen que en todas partes les tienen que hablar en castellano y que si no les hablan así es una lástima. Una lástima para los que no lo hacen. Y dudan, por esta causa, si no de la humanidad de los que no son capaces de hablar en castellano —que, a veces, también-, sí de la capacidad intelectual de los otros. Gente tan apegada a su lengua y cultura cuando salen de su terruño no puede ser considerada precisamente gente sin identidad o con identidad baja — como pretenden algunos escritores castellanos- sino todo lo contrario. Y así lo interpreta Esteva Fabregat en sus estudios sobre etnicidad en Cataluña. Piensa este antropólogo, por el contrario, que son los castellanos, entre todos los inmigrantes en Cataluña, los que más resistencia ofrecen a ceder en aquellos aspectos que — como el lenguaje- les caracterizan. Y con los que se sienten muy identificados: "El grupo étnico castellano en Barcelona — dice el conocido antropólogo- representa la mayor frecuencia de susceptibilidades etnocéntricamente definidas en comparación con la de cualquier otra región no catalana” (Esteva Fabregat 1984: 67).

Quizá, aunque eso Esteva no lo dice, sean también los que más interés demuestran en volver a su lugar de procedencia. Bien como destino definitivo, bien manteniendo o restaurando una casa en el pueblo a la que puedan regresar todos los veranos. En los pueblos de Castilla este fenómeno es bien conocido, hasta el punto de que muchas fiestas —que antes se celebraban en otras fechas del año- se han ido concentrando en los meses de agosto de modo que puedan participar en ellas los "hijos del pueblo" que regresan. Ese sentimiento de pertenencia a un lugar, su lugar, es lo que les vuelve a hacer plenamente castellanos, siendo unos seres errabundos y siempre con apetencia de volver mientras tanto. ¿Le ocurre a todo el mun- 
do? No necesariamente, no —en todo caso- con tal intensidad. Dejando de hablar su lengua, un castellano dejaría de considerarse castellano y no teniendo un lugar y una casa a la que regresar también.

La identidad — como es bien sabido - se mide, se contrasta y se modifica siempre respecto a los otros. Y los castellanos de Castilla la Vieja no son esa gente sin identidad que pretenden sus escritores y políticos — pues entonces podrían cambiarla, aunque sólo fuera temporalmente, por cualquier otra- sino más bien gente que de identidad van sobrados. El error está sin duda en confundir la consciencia regional de una Comunidad Autónoma recientemente recreada con la identidad cultural que a los castellanos les sobra. Tanto que — como suele ocurrir — sólo la redescubren cuando la ven amenazada. Si la sacaran a relucir cuando están en su tierra probablemente les iría mejor en el actual concierto de identidades que se ha montado en el Estado español. Unos lloran y otros exigen, mientras los castellanos - pensando que la cosa no va con ellos- generalmente callan. Hasta que se sienten agraviados y entonces sus políticos ya se encargan de manejar ese agravio comparativo a su favor.

IV. CODA EN CLAVE DE LEYENDA: MOROS Y CRISTIANOS INTERCAMBIANDO NIÑOS EN EL BIERZO

El cronotopo que algunos autores han tomado de lo que Bakhtin escribiera sobre la novela para referirse a "la conexión intrínseca de relaciones temporales y espaciales que se expresa de forma artística en la obra literaria" (Bakhtin 1981: 84), puede servir también para explicar las cronotopías identitarias de las que estamos hablando. El etnotexto que encabeza esta disertación creo que con ser del Alto Bierzo —y, por tanto, leonés- resume muy bien algunas de las reflexiones que llevamos hechas acerca de lo castellano. No olvidemos que el padre de Bernardo del Carpio, el dudoso héroe que "salva" a España impidiendo la entrega de León y Castilla a Carlomagno, estuvo encerrado durante años en el castillo de Luna, dentro del mismo territorio mítico. Que los romances nos presentan a Bernardo vestido a la morisca cuando, aliado con el rey moro de Zaragoza, se enfrenta a las tropas francesas y las derrota. Las leyendas sobre moros, tan frecuentes en tierras bercianas pero no menos en otras de Castilla, parecen ser —entre otras cosas- un intento de reconciliación con el pasado.

En la que aquí hemos incluido se asume explícitamente que hay moros en la costa de nuestra genealogía. Otro asunto es que los moros sean los árabes en sentido estricto y no - como ya hemos apuntado en otros trabajos (Díaz Viana 2008) - el gentil, el pagano, el no cristiano que habitó los 
mismos lugares: los paganos que fuimos. Tales historias ponen también de manifiesto un impulso de amalgamamiento, de integración: lo cristiano no niega lo pagano ni lo moro, lo castellano y leonés no excluye lo español. Todo debe tender a hacerse uno.

Y es verdad que Castilla resolvió "por las bravas" lo que hoy consideraríamos un debate entre la integración y la multiculturalidad. Pero del mismo modo que sí parece cierto que para Castilla "la unidad se hace a través de la homogeneidad", no resulta del todo justo decir que "Castilla ha olvidado entenderse con lo que es distinto a ella" y que nunca "intentó integrar las diferencias" (Hernández 2004: 19-20). Lo que proponen los mitos castellanos — si se les analiza con cuidado_ es, más bien, un mestizaje inclusivo en lo cultural, desde el que - efectivamente- no se comprende bien la obstinación en una diferencia excluyente. Es la hibridez de Castilla con lo "otro", su aglutinación progresiva, lo que produce lo español y lo hispano. Y sería el desacuerdo respecto a esta tesis integradora lo que finalmente llevara a negar —o renegar de - lo castellano y lo español. No se trata en rigor de una "nación-contrato" ni de un "genio nacional" o "genio-nación" lo que el llamado "españolismo castellano" ha propuesto, sino una integración en devenir, porque las integraciones nunca son completas ni están terminadas. No existen, desde luego, "unidades de destino en lo universal" como acostumbraba a decir en su autocomplacencia la retórica franquista. Siendo esto, precisamente, lo que ahora se está revisando y de ahí que - como realidad política y administrativa-Castilla y León (o, mejor, sus dirigentes) se muestren un tanto desorientados frente a las reivindicaciones de unos y otros.

Son los mitos castellanos, mucho más que la historia de León o de Castilla, los que contribuyeron a zurcir a España en otro tiempo y a ellos convendrá volver para discernir cuáles fueron sus triunfos y sus fracasos. Los regeneracionistas, que tanto influyeron en algunos escritores de la "Generación del 98", estaban convencidos de que regenerar o revitalizar a España pasaba por la revitalización de Castilla, quizá porque el regeneracionismo fue - en efecto- un movimiento intelectual que surgió de lo que "podríamos llamar la España interior" (Hernández 2004: 24). Pero volver a ese regionalismo castellanista $-\mathrm{O}$ nacionalismo rebajado- propuesto por Julio Senador o Macías Picavea y a sus secuelas en forma de sub-mito comuneril, no constituye seguramente ninguna solución para las cuitas de castellanos y leoneses ante el confuso presente.

El aparentemente vago gentilicio "castellano" —que hemos utilizado con profusión en este ensayo- va mucho más allá de la calificación de quienes son o residen en Castilla. Engloba a unas gentes que, con frecuencia, se pasan la mayor parte de su vida fuera de Castilla anhelando volver a su 
pequeña ciudad o pueblo. A quienes proceden de unos mitos y van, quizá, toda su existencia en pos de ellos. Mito, ritual y leyenda son — tambiénlas gentes o "la comunidad que los mantienen vivos" (Díaz Viana 1984: 11).

"Ya en 1930 la 'diáspora' castellanoleonesa representaba el 14 por 100 de los nacidos en la región y residentes en España. En 1975 esa proporción ascendía al 31 por 100. Es decir, en ese año tres de cada diez castellano-leoneses residían fuera de la región" (De Miguel y Moral 1984: 37).

Como los moros y moras de la leyenda que aquí hemos trascrito, muchos castellanos hoy se ven — al igual que los de las últimas décadas- en la necesidad de abandonar sus cuevas y escondrijos buscando dar "un porvenir a sus hijos en un mundo que ya no va a ser nunca el suyo". Lo que, por otra parte, vienen haciendo con singular esfuerzo y bastante éxito por generaciones.

\section{BIBLIOGRAFÍA CITADA}

Bakhtin, M. M. 1981. "Forms of Time and of the Chronotope in the Novel", en M. Holquist (ed.), The Dialogic Imagination: Four Essays by M. M. Bakbtin: 84-258. Austin: University of Texas Press.

Brandes, S. 2007. "Prólogo", en L. Díaz Viana y P. Tomé Martín (coords.), La tradición como reclamo: Antropología en Castilla y León: 11-14. Valladolid: Junta de Castilla y León, Consejería de Cultura y Turismo.

Caro Baroja, J. 1970. El mito del carácter nacional. Meditaciones a contrapelo. Madrid: Seminarios y Ediciones.

Cruces, F. 1997. "Desbordamientos. Cronotopías en la localidad tardomoderna". Política y Sociedad 25: 45-48.

Delibes, M. 1979. Castilla, lo castellano, los castellanos. Barcelona: Planeta.

Delibes, M. 1990. El disputado voto del señor Cayo. Barcelona: Destino,

De los Mozos, S. 1984. La norma castellana del español. Valladolid: Ámbito.

De Miguel, A. y F. Moral. 1984. La población castellana. Valladolid: Ámbito.

Díaz Viana, L. 1984. Rito y tradición oral en Castilla y León. Valladolid: Ámbito.

Díaz Viana, L. 1988. "Identidad y manipulación de la cultura popular. Algunas anotaciones sobre el caso castellano", en L. Díaz Viana (coord.), Aproximación antropológica a Castilla y León: 13-27. Barcelona: Anthropos.

Díaz Viana, L. 1995. "La construcción legendaria de la identidad. De los estereotipos sobre Castilla a la celebración de Villalar". Revista de Dialectología y Tradiciones Populares L (2): 173-194.

Díaz Viana, L. 1997. Castilla y León: Imágenes de una identidad. Notas para un manual de Etnografía. Valladolid: Ámbito.

Díaz Viana, L. 2008. "Amantes que se desvanecen en el tiempo: la memoria etnográfica o la compleja significación de las leyendas". Revista de Antropología Social (RAS) 17: 141-164.

Espinosa, A. M. 2009 [1946-47]. Cuentos populares recogidos de la tradición oral de España. Introducción y revisión de L. Díaz Viana y S. Asensio Llamas. Madrid: CSIC.

Esteva Fabregat, C. 1984. Estado, etnicidad y biculturalismo. Barcelona: Península. 
Finkielkraut, A. 1987. La derrota del pensamiento. Barcelona: Anagrama.

Hernández, A. 2004. La personalidad social de Castilla. Oviedo: Septem.

Kavanagh, W. 1994. Villagers of the Sierra de Gredos. Oxford: Berg.

Kavanagh, W. 2007. "El uso del espacio y su simbolismo en una aldea de la Sierra de Gredos", en Fundación Joaquín Díaz (ed.), La voz y la noticia. Palabras y mensajes en la tradición hispánica: 256-277. Valladolid: Junta de Castilla y León-Fundación Joaquín Díaz.

Menéndez Pidal, R. 1945. Castilla: La tradición, el idioma. Madrid: Espasa-Calpe.

Passeron, C. y J. C. Grignon. 1992. Lo culto y lo popular. Miserabilismo y populismo en sociología y literatura. Madrid: La Piqueta.

Roque, Mㄹ. A. 2008. Los nobles vecinos en el territorio de las mujeres: construcción y transmisión simbólica en las sierras castellanas y riojanas. Madrid: CSIC.

Schindler, K. 1941. Folk Music and Poetry of Spain and Portugal. Nueva York: Hispanic Institute.

Velasco, H. M. 1988. "Signos y sentidos de la identidad de los pueblos castellanos. El concepto de pueblo y la identidad", en L. Díaz Viana (coord.), Aproximación antropológica a Castilla y León: 13-27. Barcelona: Anthropos.

Fecha de recepción: 17 de octubre de 2009

Fecha de aceptación: 1 de febrero de 2010 


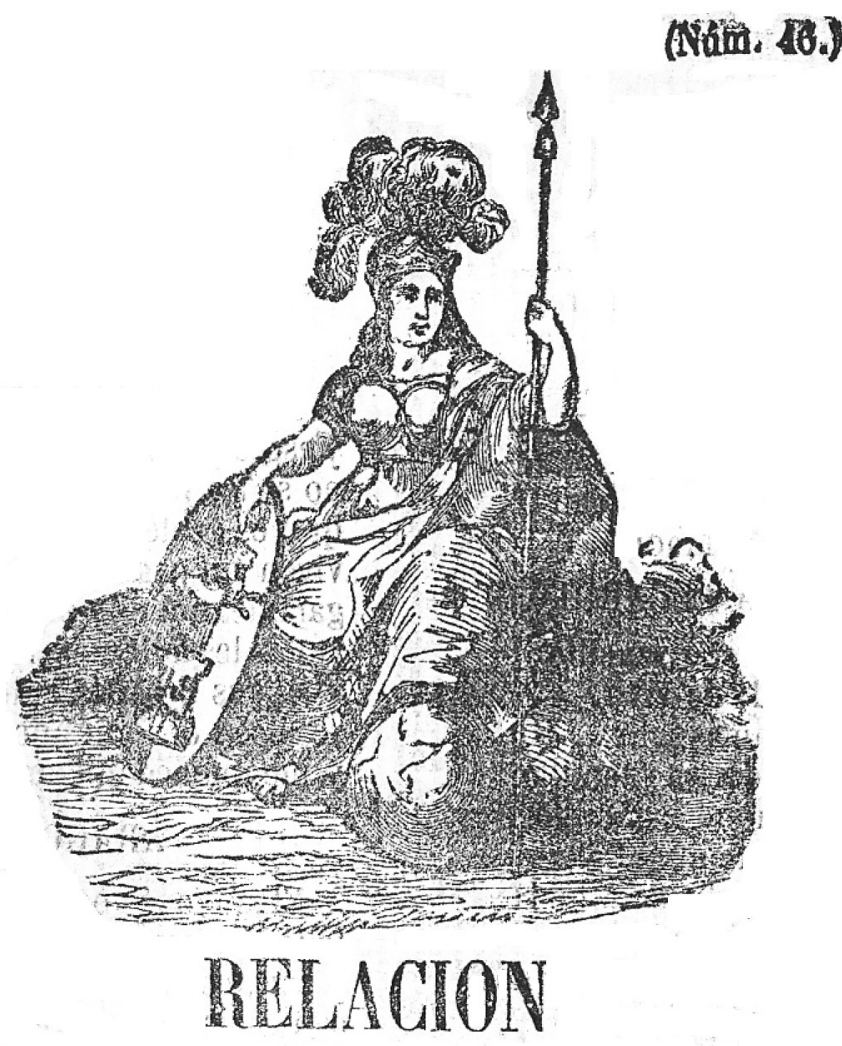

del caräcter, genio y condiciones que tienen los habitantes de las provincias de España.

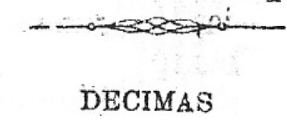

ISPAÑA.

El español es honrado. es esforzado $\mathrm{y}$ valiente, es moderado y prudente, buen marino y buen soldado; del estranjero apreciado, es generoso y sufrido, ingenioso y atrevido; ₹ con tal disposicion, por falta de aplicacion es un tesoro escondido.
CASTHLLA LA VIEJA.

Ls el castellano viejo hombre de buen corazon; y de muy sana intencion para dar un buen consejo: no es de grande despejo. es algo lerdo y mohino, y el fruto más peregrino que su sencillez encierra es solo el tue da su tierra, el pan pan, y el vino vino. 
CASTILLA LA NUEVA.

Castilla la Nueva es país sano y agradable, la gente bastante amable aunque afecta al interés; todos los campos que ves, cultivados con ardid, harán mucho mas que un Cid sin probar jamás el pan, si un año con otro dàn cebada para Madrid.

\section{LA ALCARRIA.}

El alcarreño sencillo en su modo de vivir, no sabe jamás salir de entre romero y tomillo: en cualquiera lugarcillo se cria gente muy fiel, echan los pobres la hiel trahajando como brutos, $y$ al fin sus colmados frutos es un poquito de miel.

\section{MANCHA.}

El que llegue á caminar por la Mancha con frecuencia, le enseñarán, sin falencia, la horca antes que el lugar: no gustan de trabajar; es gente de poca espera, arman presto una quimera, y nunca de hambre se mueren, pues son dueños cuando quieren de lo que tiene cualquiera.

\section{ESTREMADURA.}

Espíritu desunido domina álos extremeños, jamás entran en empeños ni quieren tomar partido: cada cual en sí metido y contento en su rincon, huye de toda instruccion; y aunque es grande su viveza, vienen á ser, por pereza, los indios de la nacion.

\section{ANDALUCIA.}

$\mathrm{Al}$ andaluz retador, y escesivo en ponderar, no se les puede negar que es gente de buen humor: viven sin pena y dolor, galantean á sus madres, jamás les faltan azares, y en sus desafios todos se dicen dos mil apodos y luego quedan compadres.

ARAGON.

El aragonés osado todas las cosas emprende, y con teson las defiende con espíritu arrestado: testarudo y porfiado á nadie cede su gloria, y para formar su historia jamás perdona fatiga, procurando así que siga su dominio y su memoria.

\section{GATALUÑa.}

El catalan bullicioso, viajero y navegante, mercader y fabricante, jamás vive con reposo: en un país escabraso á costas de mil afanes, marca tierras, hace planes, y aunque sea en un establo, al fin por arte del diablo bace de las piedras panes. 
VALENGIA.

Valencia, fuera de chanza, que infunde á todos, infiero, un espíritu ligero, muy dispuesto á la mudanza: van siempre flojos de panza, son de corazon muy frio, habilan junto á un rio, y así lienen de este modo la sustancia para todo de gente de regadío. MURCIA.

El murciano trabajando alegre en su barraquilla, al son de la guitarrilla pasa su vida cantando: él saele de cuando en cuando jugar una morisqueta, pero su atencion y cuenta es cuidar sus naranjitos, criar cuatro gusanitos, y guiar una carrela.

\section{GALICIA.}

No se les puede negar á los gallegos más legos, que vale por mil gallegos el que llega á despuntar: no prueba su paladar mas que coles y pan seco, $\checkmark$ desde el mas mozo al viejo baja el rerano á segar con gusto á todo lugar, menos al lugar de Meco.

\section{MARAGATOS.}

Los maragatos bonazos no son lirutos por un tris, pues cualguiera del país es un pobre calzonazos; venciendo mil embarazos viajan no muy aprisa con sus lienzos, y es la risa, que así, como me lo quiero. se llevan nuestro dincro, pero nos dan la camisa.

\section{LEON.}

El leonés, homibre sano, es de ordinario no mas, de carácter poco mas 6 menos que el castellano; aunque en su trato es llano tiene duro el corazon; su ruda pronunciacion le hace muy tosco y bravío, siendo con teson y brio inflexible en su opinion.

\section{MONTAÑAS DE SANTANDER.}

Es del montañés la gloria guardar como antigua prenda en una pequeña hacienda una grande ejecutoria, del noble país la historia á todo alojero embebe, y creo que se le debe al montañés esta maña, que es la nobleza de España mas cercana de la nieve.

\section{ASTURIAS.}

El asturiano cerdoso, bajo, rechonzo y cuadrado. forcejudo y mal formado, es un misto de hombre y oso:

su carácter es honroso, hombre de bien, mas sin maña, todo lo emprende con saña, es muy vano y orgulloso, y bastante perezoso para salir á campaña. 


\section{VIZCAYA.}

El vizcainó severo con dureza nunca oida, prefiere siempreả su vida la defensa de su fucro: es amigo verdadero, es un mercader honrado, es marinero arrestado; y es capaz con entereza sin cansarse la cabeza, de escribir más que un letrado.

\section{NAVARRA.}

Navarra, en realidad, da de sí la gente homrada, y aunque es un poco pesada, guardan palabra y verdad: en todo tiempo y edad son terribles comedores, igualmente bebedores, y todos son fabricantes, asenlistas, comerciantes, 6 ambulantes capadores.

\section{RIOJA.}

Es la gente riojana vividora de manera. que muy bien a otro cualquiera le pueden cardar la lana: es fuerte, robusla y sana, y tiene todo sia gozo, desde el mas viejc al mas inozo, vivir en campaña rasa: y abandonando su casa pasar la vida en un ehozo.

\section{NADRID.}

Aun las personas más sanas que son en Madrid nacidas, tienen que hacer sus comidas de pildoras y tisanas! diamantes como avellanas, estirado.corbatin, ricos trajes y espadin suele ser su adorno bello, mas siempre marcado el cuello con sello de Anton-Martin

\section{MALLORCA.}

Del mallorquin el tesoro es el aceile y el vino, aborrece al argelino y á toda casta de moro; ama la plata y el oro, y guarda bien su peculio; todo el año es mes de julio. y con rara devocion da culto y veneracion á su Raimundo de Lulio.

$$
\text { ISLAS CANARIAS. }
$$

El canario siempre vago, buscando en el mar su vida hace toda su comida con un plátano y un trago: trata al inglés con halago y le da el fruto que encierra su fértil y hermosa tierra; y así viene á estar con maña, sujeto al rey de España y amigo del de Inglaterra. ISLA DE CUBA.

El indiano, con ardid vence mil riesgos, y gana mucho dinero en la Habana para gastarlo en Madrid; él vive en continua lid, y su gran manía es con todo el afan que ves, en ser pretendiente eterno de un condado, de un gobierco, $\delta$ un tíkulo de marqués.

MADRID. -Despacho, calle de Juanielo, núm. 19. 
